\title{
CONTINGÊNCIAS OCUPACIONAIS COM MATERIAL BIOLÓGICO ENTRE PROFISSIONAIS DE ENFERMAGEM
}

\section{REVISÃO INTEGRATIVA}

SILVA, Francisca Renata Rayanne da Costa ${ }^{1}$

SILVA, Francisca Renata Rayanne da Costa. Contingências ocupacionais com material biológico entre profissionais de enfermagem. Revista Científica Multidisciplinar Núcleo do Conhecimento. Ano 05, Ed. 03, Vol. 08, pp. 37-47. Março de 2020. ISSN: 2448-0959, Link de acesso: https://www.nucleodoconhecimento.com.br/saude/contingenciasocupacionais

\section{RESUMO}

Os ocupacionais do setor de enfermagem vivem constantemente sujeito ao perigo de exteriorização a material biológico em seu âmbito de exercício. O corrente plano teve como finalidade verificar a natureza das contingências trabalhistas com substâncias e aparatos biológicos em colaboradores de enfermagem. Método: trata-se de um estudo de revisão integrativa com delimitação de período entre 2005 a 2015, em português, utilizando as seguintes palavras-chave: Risco ocupacional, Exposição ocupacional e Notificação de Acidente de Trabalho, foram selecionados 7 artigos. Resultados: os estudos demonstraram que a categoria profissional mais exposta foi a dos técnicos de enfermagem (50\%) seguida dos enfermeiros (25,3\%). Conclusão: Apesar das ocorrências com exteriorização a material biológicos em ocupacionais de enfermagem ter sido bastante explorado nas literaturas consultadas, evidenciou-se que necessidade de implementar um programa de educação permanente e normas de

1 Enfermeira clínica, pós graduada em enfermagem clínica/urgência e emergência/UTI. 
biossegurança, atenuando assim os riscos de contaminação aos profissionais de enfermagem.

Palavras-chave: Risco ocupacional, exposição ocupacional, notificação de acidente de trabalho.

\section{INTRODUÇÃO}

Segundo o Ministério da Previdência e Assistência Social delineia como desastre de ofício a ocorrência durante a execução do trabalho ou no trajeto a serviço da empresa, o qual provoca contusão corpórea ou crise viável que cause decesso, a perda ou a redução imutável ou temporânea da habilidade para o trabalho. (BRASIL, 2000).

Os colaboradores do campo de atuação da saúde estão reiteradamente sujeitos as ameaças de contagiar-se com diversas infecções em seu âmbito de exercício, considera-se que as instituições de saúde são reputadas como zonas insalubres visto que expõe frequentemente o profissional a variados riscos ocupacionais, nesse estudo destaca-se o risco biológico.

Considera-se Risco Biológico (RB) a exequibilidade de contato com aparato biológico, como sangue ou outros fluidos orgânicos, que são iminentemente capazes de propagar agentes biológicos causadores de danos á saúde do indivíduo (BRASIL, 2005).

Alguns autores consideram o RB que os colaboradores da saúde estão expostos no decorrer das funções laborativas tem se agravado, formidavelmente, nas últimas décadas, devido a diversas razões como resistência microbiana, emergência de novas doenças e o retorno de outras como a tuberculose, dentre outros fundamentos.

A exposição ocupacional ao RB não se restringe somente aos hospitais, recentemente estudos acerca dos riscos ocupacionais dos colaboradores do ramo da saúde na rede de atenção básica a saúde tem revelado que nesses locais existem a possibilidade de exposição ao trabalhador dos mesmos riscos que o âmbito hospitalar. 
Dentre as razões que contribuem para essa ocorrência, pode-se ressaltar a peripécia dos dirigentes de enfermagem serem o maior staff entre os trabalhadores da saúde por executar atividades nas 24 horas de serviço incessável, operar a maior capacidade de procedimentos junto ao paciente e cumprir técnicas invasivas em grande maioria dos atendimentos.

Entre os diversos patógenos de superior relevância concatenado à exposição ocupacional, salienta-se o vírus da imunodeficiência humana (HIV), vírus da hepatite B (HBV) e o vírus da hepatite C (HCV). Nesse enquadramento, a hepatite B é a patologia que denota maior preponderância, porém a síndrome da imunodeficiência humana (AIDS) é a que causa maior inquietação aos profissionais.

Com a destinação de restringir o risco de inoculação por patógenos, é elementar a adoção de parâmetros preventivos pré e pós exposição a acidentes ocupacionais com substâncias e aparatos biológicos, sendo as circunspeções padrões as primordiais medidas.

No ano de 2005, o Ministério do Trabalho do Brasil proferiu a Norma Regulamentadora (NR-32) do Programa de Controle Médico de Saúde Ocupacional (PCMSO). Este preceito pressupõe a orientação dos trabalhadores iminentemente expostos com propriedade para o risco a que está adstritos, contanto, não se pressupõe um método de sentinela epidemiológica sistemática. A NR ressalta que as contingências com substâncias e aparatos biológicos devam ser classificados como emergências, uma vez que os parâmetros profiláticos quando estabelecidos e implantados em tempo ágil, têm êxito constatado.

Dentro deste contexto, a pesquisa tem como objetivo identificar o perfil das contingências ocupacionais com exposição à substâncias e aparatos biológicos em profissionais de enfermagem, que poderá nortear futuras pesquisas no desenvolvimento de ações que tenham como objetivo a efetivação de um programa de ensino continuado, bem como contribuir abordando os principais fatores de biossegurança e responsabilidade social, evidenciando que a não existência desses fatores será determinante para o maior acometimento do risco ocupacional. 


\section{METODOLOGIA}

Trata-se de estudo de revisão integrativa de literatura, de forma a investigar estudos já publicados, revisando a alcançar conclusões acerca de uma tônica particular. É reputada uma tática empregada para constatar os indicativos presentes, solidando a execução de saúde nas dissemelhantes singularidades (WHITTEMORE, 2005). Foram adotados os seguintes dispositivos metodológicos:

Caracterização da questão e dos propósitos da recapitulação; estabelecimento dos parâmetros para distinção dos artigos; catalogação dos ensinamentos; mensuração dos estudos na retificação integrativa e verificação dos dados e apresentação da resultância (WHITTEMORE, 2005).

Como questão norteadora adotou-se: Qual a frequência que ocorre acidentes ocupacionais com exposição a substâncias e aparatos biológicos em trabalhadores de enfermagem? Para seleção dos artigos foi utilizado à base de dados: Literatura Latino - Americana e do Caribe em Ciências da Saúde (LILACS).

Os parâmetros de incorporação definidos foram temas de periódicos disseminado em português, sendo utilizadas nas buscas as seguintes palavras-chave: Exposição ocupacional, Risco ocupacional e Notificação de acidente de trabalho. Com resumos disponíveis na base de dados selecionados, no período compreendido entre 2005 e 2015.

Para verificação e pospositiva síntese dos artigos que deferiram os parâmetros de inclusão, foi elaborado um quadro sinótico, que contemplou os seguintes aspectos: no do artigo, ano de publicação, idioma, país do estudo e descrição dos estudos.

$\mathrm{Na}$ busca realizada com as palavras-chave, encontrou-se um cômputo demasiado de artigos, totalizando 4.259 textos completos. Destes 2.448 não existiam à disposição na íntegra, restando 1.811 para análise inicial. Após refinamento inicial considerandose os critérios de exclusão, 1.548 textos foram excluídos por estarem fora do tema do estudo e somente 263 textos tiveram seus resumos analisados. O quantitativo de 23 
textos foram lidos na íntegra e foram excluídos 16 textos, restando uma matriz de síntese que respondia ao objetivo do estudo de 07 artigos.

\section{RESULTADOS E DISCUSSÃO}

Os estudos foram apresentados e discutidos de acordo com dois eixos: eixo 1 Acidentes ocupacionais com exposição a material biológico e eixo 2 - Perfil dos acidentes ocupacionais com exposição a material biológico em trabalhadores de Enfermagem.

Eixo 1: Perfil dos estudos sobre acidentes ocupacionais com material biológico.

Quadro 1 - Distribuição dos artigos segundo o ano de publicação, a base de dados, o idioma e o país da exploração - Brasil - 2005 a 2015.

\begin{tabular}{|ccccc|}
\hline $\mathbf{N}^{\circ}$ & Ano de Publicação & $\begin{array}{c}\text { Base de dados/Modelo } \\
\text { para publicação eletrônica }\end{array}$ & Idioma & $\begin{array}{c}\text { Pais da } \\
\text { Pesquisa }\end{array}$ \\
\hline 01 & 2009 & LILACS & Português & Brasil \\
02 & 2009 & LILACS & Português & Brasil \\
03 & 2010 & LILACS & Português & Brasil \\
05 & 2011 & LILACS & Português & Brasil \\
05 & 2011 & LILACS & Português & Brasil \\
06 & 2014 & LILACS & Português & Brasil \\
07 & 2014 & LILACS & Português & Brasil \\
\hline
\end{tabular}

Fonte: Elaborado pela autora, 2015.

O quadro 1 mostra a distribuição dos 7 artigos utilizados na pesquisa, selecionados em conformidade com o ano de divulgação: 2 (28,58\%) artigos publicados em 2009; 1 (14,26\%) em 2010; 2 (28,58\%) em 2011 e 2 (28,58\%) em 2014.

Com relação ao idioma 7 (100\%) artigos utilizados para esta pesquisa foram publicados em português. Todos os artigos foram publicados em periódicos brasileiros. 
No Brasil, as contingências ocupacionais com substâncias e aparatos biológicos estão associados principalmente aos fatores de risco a equipe de enfermagem. Observouse na pesquisa que grande parte dos estudos procura identificar a frequência dos acidentes com MB e os fatores associados ao seu acontecimento.

A organização dos autores e periódicos com obras sobre Acidentes ocupacionais com MB publicados no período de 2005 a 2015 é apresentada no quadro 2.

Quadro 2 - Distribuição dos artigos selecionados segundo os periódicos em que foram publicados - Brasil - 2005 a 2015.

\begin{tabular}{|c|c|c|}
\hline $\mathbf{N}^{\circ}$ & Autores & Periódico \\
\hline 01 & $\begin{array}{l}\text { Almeida, ANG; Tripple, AFV; Souza, ACS; } \\
\text { Brasileiro ME. }\end{array}$ & Rev. Brasileira de Enfermagem. \\
\hline 02 & $\begin{array}{l}\text { Camara, PF; Lira, C; Santos, JBJ; Vilella, } \\
\text { TAS; Hinrichsen, SL. }\end{array}$ & Rev. Brasileira de Enfermagem. \\
\hline 03 & $\begin{array}{l}\text { Giancotti, GM; Haeffner, R; Solheid, NLS; } \\
\text { Miranda, FMA; Sarquis, LMM. }\end{array}$ & $\begin{array}{l}\text { Epidemiologia-Serviço e } \\
\text { Saúde. }\end{array}$ \\
\hline 04 & $\begin{array}{l}\text { Guilarde, AO; Oliveira, AM; Tarssara, M; } \\
\text { Oliveira, B; Andrade SS. }\end{array}$ & Rev. de Patologia Tropical \\
\hline 05 & Júlio, RS; Filardi, MBS; Marziale MHP. & Rev. Brasileira de Enfermagem. \\
\hline 06 & Machado, MRM; Machado FA. & Rev. Brasileira de Saúde \\
\hline 07 & $\begin{array}{l}\text { Soerense, AA; Moriya, TM; Havashida, M; } \\
\text { Robazzi, MLCC. }\end{array}$ & $\begin{array}{l}\text { Ocupacional. } \\
\text { Rev. Brasileira de Enfermagem. }\end{array}$ \\
\hline
\end{tabular}

Fonte: Elaborado pela autora, 2015.

O quadro 2 mostra que dos 7 periódicos que apresentam obras sobre contingências trabalhista com exposição a MB, 4 (70\%)foram publicados na revista Brasileira de Enfermagem, 1(10\%) na revista de Patologia Tropical, 1(10\%) na revista Brasileira de Saúde Ocupacional e 1(10\%) em Epidemiologia-serviço e Saúde.

O quadro 3 descreve os estudos sobre acidentes ocupacionais com exposição a MB. 
Quadro 3 - Descrição dos estudos sobre acidentes ocupacionais com exposição a material biológico.

\begin{tabular}{|ll|}
\hline $\mathbf{N}^{\circ}$ & Descrição dos Estudos \\
\hline 01 & $\begin{array}{l}\text { Caracterização do perfil das publicações a cerca do risco biológico entre } \\
\text { trabalhadores de enfermagem. }\end{array}$ \\
02 & $\begin{array}{l}\text { Mostra a freqüência de exposição acidental a material biológico potencialmente } \\
\text { contaminado. }\end{array}$ \\
03 & $\begin{array}{l}\text { Avaliação dos acidentes profissionais com MB entre profissionais do hospital das } \\
\text { clínicas/UFG. }\end{array}$ \\
04 & $\begin{array}{l}\text { Identificação dos acidentes de trabalho com MB ocorrido com trabalhadores de } \\
\text { enfermagem do hospital geral de Palmas/TO. }\end{array}$ \\
05 & $\begin{array}{l}\text { Análise da ocorrência de acidentes com MB entre profissionais da saúde de uma } \\
\text { unidade hospitalar. } \\
06\end{array}$ \\
Descrição das características dos acidentes com MB no estado do Paraná/PR. \\
Identificação do perfil dos acidentes com exposição a MB em Minas gerais/MG.
\end{tabular}

Fonte: Elaborado pela autora, 2015.

A pesquisa realizada evidenciou que grande parte dos artigos identificou as características, frequência e os fatores relacionados ao acometimento, ela mostra o preponderante fator de contingências trabalhistas com exibição a substâncias biológicas em profissionais da saúde, estar relacionada ao fato de possuir mais contato na assistência, também ao tipo e a frequência de procedimentos.

As formas de exibição são diversas e abrangem: lesões por objetos perfurantes ou que estejam infectados, exibição de mucosa ou contato com sangue e/ou outros fluidos e secreções iminentemente infectadas em incisões cutâneas pregressas.

Entre as patologias obtidas por meio de contingências com substâncias e aparatos biológicos a hepatite $B$ é a de maior ameaça. A incidência de trabalhadores descobertos para este vírus oscila de $6 \%$ a $30 \%$, podendo chegar até a $60 \%$, dependendo da circunstância do paciente-fonte. Em relação à hepatite $\mathrm{C}$, a ameaça de propagação após exibição percutânea à substâncias biológicas é cerca de 1,8\%, 
podendo alternar entre $0 \%$ a $7 \%$. Quanto ao HIV estima-se em $0,3 \%$ o risco de contágio após exibição percutânea e em 0,9\% o risco de exibição mucocutânea.

Eixo 2: Frequência dos acidentes ocupacionais com exposição a materiais biológicos entre os trabalhadores de Enfermagem.

Em relação a periodicidade que intercorrem as contingências trabalhistas com exposição à substâncias biológicas, os estudos mostraram o perfil das contingências com exposição à substâncias e aparatos biológicos segundo a ocupação em conformidade com a categoria notificada através da Comunicação de Acidentes de Trabalho (CAT).

Os estudos mostraram que a categoria profissional que representou percentual de maior risco nos estados de Goiás, Tocantins, Paraná e Minas Gerais foram os técnicos de enfermagem, seguidos dos enfermeiros e outros profissionais da saúde.

Em Goiás, 69,2\% técnicos de enfermagem; 19,9\% enfermeiros; outros profissionais da saúde 10,9\% (GUILARDE et al, 2010). Palmas, 75,4\% técnicos de enfermagem; 17,2\% enfermeiros; outros profissionais da saúde 7,4\% (MACHADO; MACHADO, 2010). Paraná, $62 \%$ técnicos de enfermagem; $25,7 \%$ enfermeiros; outros profissionais da saúde 12,3\% (GIANCOTTI et al, 2014). Minas Gerais, 73,4\% técnicos de enfermagem; 16,3\% enfermeiros; outros profissionais da saúde 10,3\%(JULIO; FILARDI; MARZIALE,2014).

Isso é facilmente explicado pelo fato dos técnicos permanecerem maior parte do tempo junto à assistência ao paciente e executarem a grande maioria dos procedimentos invasivos, sendo o perfuro cortante um dos fundamentais dispositivos de trabalho na aplicação, portanto, propenso a infecção com fluidos biológicos infectados por patógenos como HIV e os vírus das hepatites.

Os fatores de risco estão diretamente relacionados ao acometimento do acidente ocupacional com MB, sendo eles: emergência, agitação do paciente, falta de atenção, estresse, pressa, entre outros. 
É indispensável que se designe um paradigma para padrões de cautela que devem ser empregadas na assessoria a todos os pacientes, independentemente do diagnóstico definido da patologia infecciosa. Esses parâmetros abrangem a aplicação dos equipamentos de proteção individual (EPI), conforme o arquétipo de contato estipulado com o paciente (luvas, máscaras, goros, óculos de proteção, capotes e calçados fechados) e cautela no manejo de material perfuro cortantes.

Existe muito descaso com tais equipamentos, tanto por parte dos trabalhadores, que mesmo tendo acesso aos equipamentos não usam em procedimentos, quanto por parte das instituições de saúde que não disponibilizam para os funcionários, ou quando fazem são inadequados ou insuficientes. Os fatores que interferem no uso dos EPIS são: confiabilidade da equipe nos equipamentos, desconhecimento sobre o uso correto, estímulo para utilizá-los, desinteresse em seu auto cuidado, e ligado a esses fatores estão às condições impróprias de trabalho e o descaso dos gestores institucionais.

Em 2005, o Brasil, através da portaria № 485, instituiu a Norma Regulamentadora 32 (NR 32), com o objetivo de implementar diretrizes para a saúde dos profissionais dos serviços de saúde. A portaria № 1.748 de agosto de 2011, estabelece mais adequadamente os termos utilizados e trata do esquema de precaução de Riscos de Acidentes com Material Perfuro cortantes.

Considerando a necessidade de alcançar informações de forma metódica obter dados de forma mais sistemática para orientar as ações de precauções das doenças e degradação a saúde do trabalhador no Brasil, os casos de contingências com exposição a substâncias e aparatos biológicos passaram a ser inteirados no Sistema de Informação de Agravos de Notificação (SINAN) através da portaria nº 777/GM de 28 de abril de 2004.

\section{CONCLUSÃO}

Os achados dos estudos apontaram que os acidentes de trabalho com exteriorização a substâncias e aparatos biológicos envolvem principalmente a equipe de 
enfermagem, em destaque os técnicos que estão diretamente na assistência ao paciente. Constatou-se que muitos dos acidentes sucederam-se em serventia do descarte indevido de materiais perfuro cortantes, consequentemente, potencializado a ameaça de contrair enfermidades infectocontagiosas.

Os acidentes ocorridos foram nos tipos de contatos: a maioria na pele íntegra; percutâneo; mucosa e pele lesada. O sangue, agente contaminante, aparece na maioria das exposições, favoreceram essas ocorrências as situações de emergência, agitação do paciente e do estresse do profissional.

Os periódicos estudados que trataram do assunto mostraram que as contingências trabalhistas com substâncias e aparatos biológicos poderiam ser precavidas por meio da efetivação dos parâmetros de biossegurança estabelecidos pela NR32. Ressaltaseque a utilização dos EPIS em procedimento que envolva fluidos biológicos deve ser obrigatória.

Frente à frequência de exposição as contingências trabalhistas com substâncias e aparatos biológicos, a implantação de um plano de educação continuada é imprescindível não somente para estimular a aquisição de conhecimento, mas também para estimular os profissionais a ponderarem sobre a sua aplicação, biossegurança e responsabilidade social.

\section{REFERÊNCIAS}

ALMEIDA, André Nunes Gomes de, et al. Risco biológico entre os trabalhadores de enfermagem.Rev. bras. Enferm. v. 17, n.4, p. 595-00, dez. 2009. Disponível em: <http://www.scielo.br/ >. Acesso em: 12 out. 2015.

BRASIL, Ministério da Saúde. Secretaria de Políticas de Saúde. Doenças Relacionadas ao Trabalho:Manual de Procedimentos para serviços de saúde. Brasília: MS, 2000. 
BRASIL, Ministério do Trabalho. Portaria № 485, de 11 de Novembro de 2005. Aprova a Norma Regulamentadora 32: Segurança e Saúde no Trabalho em Serviço de Saúde. Brasília: MS, 2005.

CÂMARA, Priscila Ferreira, et al. Investigação de acidentes biológicos entre profissionais da equipe multidisciplinar de um hospital. Rev. bras. enferm. Brasília, v. 19, n. 4, p. 583-586, dez. 2011. Disponível em:<http://www.scielo.br/ >. Acesso em: 30 out. 2015.

GIANCOTTI, Geanna Mendonça, et al. Caracterização das vítimas e dos acidentes de trabalho com material biológico atendidas em um hospital público do Paraná. Epidemiol. Serv. Saúde. Brasília, v.23, n.2, p. 337-34, jun. 2014.Disponível em: <http://www.scielo.br/ >. Acesso em: 30 out. 2015.

GUILARDE, Adriana Oliveira, et al.Acidente com material biológico entre profissionais de um Hospital Universitário em Goiânia.Rev. patol. Tropic.v. 39, n. 2,p. 131-136, jun. 2010.Disponível em: <http://www.scielo.br/ >. Acesso em: 30 out. 2015.

JULIO, Renata Siqueira; FILARDI, Monique Borsato Silva; MARZIALE, Maria Helena Palucci. Acidentes de trabalho com material biológico ocorridos em municípios de Minas Gerais. Rev. bras. enferm. Brasília, v. 67, n. 1, p. 119-126, fev. 2014.Disponível em:<http://www.scielo.br/>. Acesso em: 30 out. 2015.

MACHADO, Maria do Rosário Mascaro; MACHADO, Fernando de Almeida. Acidentes com material biológico em trabalhadores de enfermagem do Hospital Geral de Palmas. Rev. bras. saúde ocup. São Paulo,v. 36, n. 124, p. 274-281, dez. 2011. Disponível em: <http://www.scielo.br/ >. Acesso em: 30 out. 2015.

SOERENSEN, Andrea Alves,et al.Acidente com material biológico em profissionais do atendimento pré hospitalar móvel.Rev. bras. Enferm. v. 17, n. 2, p. 234-239, jun. 2009. Disponível em: <http://www.scielo.br/ >. Acesso em: 12 out. 2015.

WHITTEMORE, R.; KNAFL, K.The integrative review: updated methodology. JournalofAdvancedNursing, v. 52, n. 5, p. 546-553, 2005. 
Enviado: Fevereiro, 2020.

Aprovado: Março, 2020. 